\title{
THE EFFECT OF LEARNING MOTIVATION ON LEARNING OUTCOMES THROUGH JIGSAW TYPE COOPERATIVE MODEL AT GRADE V SD RK BUDI LUHUR MEDAN
}

\author{
Sukly $^{1}$, Regina Sipayung ${ }^{2}$, Ester J. Simarmata ${ }^{3}$, Darinda Sofia Tanjung ${ }^{4}$ \\ 1,2,3,4 Universitas Katolik Santo Thomas, Medan, Indonesia \\ Isuklisinaga5330@gmail.com, ${ }^{2}$ frederika_sip@yahoo.co.id, ${ }^{3}$ ejulinda82@gmail.com, ${ }^{4}$ darindasofiatanjung@gmail.com
}

\begin{abstract}
This study aimed to determine the effect of learning motivation on learning outcomes through a jigsaw type cooperative model on Theme 8 at Grade $V$ SD RK Budi Luhur Medan. The research method used was an experimental type of quantitative research. The data were obtained by using data collection tools in the form of documentation, a questionnaire of 25 statements and 33 questions. The research was conducted at grade V SD RK Budi Luhur Medan on 20 to 21 May 2021. The number of samples were 35 students selected by saturated sampling technique. Based on statistical analysis of the data, it was obtained that the results of learning motivation questionnaire with student enthusiasm were $48 \%$ in very high category and the results of the pretest were answered by students was an average value of 65.8 in moderate category. Furthermore, the results of the post test scores obtained by students from the answers was an average value of 86.74 with very good category. The results of the correlation analysis of the influence of learning motivation on learning outcomes through Jigsaw Cooperative model obtained a correlation value of $r_{\text {count }}=0.880$ with rt $t_{\text {able }}=0.334$. Thus, the value of $r_{\text {count }}$ was higher than the value of $r_{\text {table }}$, so the correlation was very significant. Hypothesis testing with $t$-test obtained $t_{\text {count }}=10,618 t_{\text {table }} 1,697$. It was concluded that there was a significant influence between learning motivation on learning outcomes through Jigsaw Cooperative Model.
\end{abstract}

Keywords: learning motivation, jigsaw type cooperative model, learning outcomes

\section{PENGARUH MOTIVASI BELAJAR TERHADAP HASIL BELAJAR TEMA 8 MELALUI MODEL COOPERATIVE TIPE JIGSAW KELAS V SD RK BUDI LUHUR MEDAN}

\begin{abstract}
ABSTRAK
Penelitian ini bertujuan untuk mengetahui Pengaruh motivasi belajar terhadap hasil belajar Tema 8 melalui model cooperative tipe jigsaw Kelas V SD RK Budi Luhur Medan. Peneliti memiliki tujuan dalam penelitian yaitu untuk mengetahui motivasi belajar siswa kelas V, mengetahui hasil belajar siswa dengan menggunakan model Cooperative Tipe Jigsaw di kelas $\mathrm{V}$, dan mengetahui apakah ada pengaruh motivasi belajar dan hasil belajar menggunakan model Cooperative Tipe Jigsaw di SD RK Budi Luhur Medan Denai. Metode penelitian yang digunakan adalah eksperimen jenis penelitian kuantitatif. Untuk memperoleh data yang diperlukan menggunakan alat pengumpulan data berupa dokumentasi, angket 25 pernyataan dan soal 33 pertanyaan. Penelitian di SD RK Budi Luhur Medan pada kelas v dilaksanakan pada tanggal 20 sampai 21 Mei 2021 . Jumlah sampel sebanyak 35 siswa berdasarkan teknik sampling jenuh. Berdasarkan analisis statistik data diperoleh hasil angket motivasi belajar dengan minat semangat siswa sebesar $48 \%$ dengan kategori sangat tinggi dan hasil pre-test yang dijawab siswa dengan nilai rata-rata 65.8 dengan kategori cukup. Selanjutnya hasil nilai post test yang diperoleh siswa dari jawaban dengan nilai rata-rata 86.74 dengan kategori baik sekali. Hasil analisis korelasi pengaruh motivasi belajar terhadap hasil belajar melalui model Cooperative Tipe Jigsawdiperoleh nilai korelasi $\mathrm{r}_{\text {hitung }}=0.880$ dengan $\mathrm{r}_{\text {tabel }}=0.334$. Dengan demikian nilai $\mathrm{r}_{\text {hitung }}$ lebih besar dari pada nilai $\mathrm{r}_{\text {tabel }}$ maka korelasi sangat signifikan. Uji hipotesis dengan uji diperoleh $t_{\text {hitung }}=10.618 t_{\text {tabel }} 1.697$. Dapat disimpulkan bahwa adanya pengaruh yang signifikan antara motivasi belajar terhadap hasil belajar melalui model Cooperative Tipe Jigsaw.
\end{abstract}

Kata Kunci: motivasi belajar, model cooperative tipe jigsaw, hasil belajar

\begin{tabular}{|c|c|c|}
\hline Submitted & Accepted & Published \\
\hline 27 Juni 2021 & 01 September 2021 & 14 September 2021 \\
\hline
\end{tabular}

\begin{tabular}{|l|l|c|c|}
\hline Citation & $:$ & $\begin{array}{r}\text { Sukly, S., Sipayung, R., Simarmata, J. E., \& Tanjung, D. S. (2021). The Effect of Learning Motivation on Learning } \\
\text { Outcomes through Jigsaw Type Cooperative Model at Grade V SD RK Budi Luhur Medan. Jurnal PAJAR } \\
\text { (Pendidikan dan Pengajaran), 5(5), 1278-1285. DOI : http://dx.doi.org/10.33578/pjr.v5i5.8454. }\end{array}$ \\
\hline
\end{tabular}

\section{PENDAHULUAN}

Pendidikan adalah salah satu hal terpenting dari kehidupan setiap manusia yang tidak lepas dari kegiatan proses mengajar, yang dapat mengubah karakter seseorang menjadi lebih baik. Menurut Simarmata, Dkk (2020) pendidikan memiliki peran yang sangat penting dalam 
kehidupan untuk meningkatkan sumber daya manusia ke arah yang lebih baik,. Pendidikan di sekolah dasar merupakan landasan suatu pendidikan karena di sekolah dasar inilah anak anak akan diajarkan membaca, menulis dan pembentukan karakter. Dengan itu guru-guru harus mampu mengembangkan pengetahuan, sikap dan keterampilan anak menjadi lebih baik lagi dan layak bersaing di dalam bidang apa pun nantinya.

Kegiatan belajar mengajar sebagai salah satu masalah rutin yang umumnya dilaksanakan guru di kelas, bukanlah suatu yang berdiri sendiri akan tetapi terkait dengan proses pembelajaran yang terjadi di dalam kelas. Seperti guru menyediakan alat peraga dan media pembelajaran yang bisa menarik perhatian siswa agar lebih tertarik lagi untuk belajar. Aunurahman (2014: 33) berpendapat belajar adalah aktivitas kehidupan manusia sehari-hari hampir tidak pernah dapat terlepas dari kegiatan belajar, baik ketika seseorang melakukan aktivitas sendiri, maupun di dalam suatu kelompok tertentu.

Salah satu masalah yang dihadapi siswa yaitu Kurangnya motivasi yang diberikan guru kepada siswa untuk meningkatkan aktivitas belajar siswa. Begitu juga dalam lingkungan sekolah motivasi belajar diperlukan oleh seorang siswa, hal ini bertujuan agar seorang siswa dapat melaksanakan kewajibannya yaitu belajar dengan baik. Dan masalah selanjutnya guru yang cendrung metode ceramah dan diskusi sehingga membuat siswa merasa bosan, jenuh dan mengantuk. kemudian siswa mengalami kesulitan untuk mengungkapkan kembali dari isi materi yang mereka pelajari.

Tentunya peneliti memiliki tujuan dalam penelitian yaitu untuk mengetahui motivasi belajar siswa, mengetahui hasil belajar siswa dengan menggunakan model Cooperative Tipe Jigsaw di kelas $\mathrm{V}$, dan mengetahui apakah ada pengaruh motivasi belajar dan hasil belajar menggunakan model Cooperative Tipe Jigsaw di SD RK Budi Luhur Medan Denai.

Di lingkungan sekolah motivasi belajar sangat diperlukan oleh seorang siswa, hal ini bertujuan agar seorang siswa dapat melaksanakan kewajibannya yaitu belajar dengan baik. Semakin banyak dorongan atau motivasi yang diberikan kepada siswa, maka akan semakin besar pula pengaruhnya terhadap prestasi belajar siswa. Motivasi adalah suatu dukungan atau semangat diberikan kepada seseorang yang didorong oleh adanya tujuan dan keinginan. Kompri (2018: 229) mengemukakan bahwa motivasi adalah suatu perubahan energi di dalam pribadi seseorang yang ditandai dengan timbulnya afektif (perasaan) dan reaksi untuk mencapai tujuan.

Penggunaan model pembelajaran bervariasi dapat membuat suasana pembelajaran menjadi aktif. Model pembelajaran Cooperative Tipe Jigsaw salah satu yang bisa digunakan oleh guru. Model Cooperative Tipe Jigsaw adalah model pembelajaran Cooperative yang di desain untuk meningkatkan rasa tanggung jawab siswa terhadap pembelajaran sendiri dan juga pembelajaran orang lain. Menurut Muliawan (2016: 50) berpendapat tentang model pembelajaran adalah tekni pembelajaran yang memusatkan perhatian pada kemampuan penguasaan materi pelajaran tertentu secara spesifik. Siswa tidak hanya mempelajari materi yang diberikan, tetapi mereka juga harus siap memberikan dan mengajarkan materi tersebut kepada kelompoknya.

Berdasarkan permasalahan yang tertulis di atas, maka peneliti tertarik melakukan penelitian untuk melihat apakah dengan memberikan semangat, dukungan, dorongan dan menggunakan model yang akan diterapkan memiliki pengaruh dan meningkatkan hasil belajar siswa yang diharapkan.

\section{METODE PENELITIAN}

Metode penelitian adalah cara atau langkah-langkah yang sistematis dalam mengumpulkan data. Sugiyono (2017: 2) menyatakan bahwa "Metode penelitian pada dasarnya merupakan cara ilmiah untuk mendapatkan data yang valid dengan tujuan dapat ditemukan, dikembangkan, dibuktikan, dengan kegunaan tertentu". Untuk melakukan penelitian ini dilakukan dengan proses secara bertahap yaitu: Tahap Perancanaan dimana pada tahapan ini peneliti memulai dari sekolah yang menjadi objek penelitian dan menemukan penyebab rendahnya 
hasil belajar siswa, kemudian Tahap pelaksanaan dimana dilakukan memberikan dorongan dan semangat kepada siswa dan melakukan proses belajar mengajar di dalam kelas menggunakan Cooperative Tipe Jigsaw, selanjutnya Pembuatan Laporan penelitian merupakan langkah yang menentukan apakah penelitian ini sudah dilakukan baik atau belum.

Penelitian dapat memberikan petunjuk atau arahan yang sistematis kepada peneliti tentang kegiatan apa yang harus dilakukan, kapan akan dilakukan dan bagai mana cara melakukan. Penelitian ini menggunakan metode eksperimen, menurut Sugiyono (2017: 72) metode eksperimen yaitu sebagai metode penelitian yang digunakan untuk mencari pengaruh perlakuan tertentu terhadap yang lain dalam kondisi terkendalikan. Dengan kata lain metode penelitian eksperimen diartikan sebagai metode penelitian yang digunakan untuk mencari pengaruh perlakuan tertentu terhadap yang lain dalam kondisi yang terkendalikan penelitian ini merupakan penelitian Pre-eksperimen Design dengan rancangan One group pretest-posttest. Teknik pengumpulan data dalam penelitian ini dengan menggunakan data yang diperoleh dari sekolah yang berupa angket motivasi belaja, soal sebagai data utama dan studi dokumentasi sebagai data pendukung. Peneliti menggunakan pengumpulan data dengan uji validitas Uji validitas adalah pengujian suatu alat ukur yang digunakan untuk mengukur variabel yang ada. Arikunto (2018: 211) validitas adalah ukuran yang menunjukkan tingkat-tingkat valid atau kesalihan sesuatu instrument, Uji reliabilitas yaiyu untuk melihat atau menukur kosisten dari sebuah instrumen harus sama isinya, respondennya sama, dan waktu yang berbeda, uji normalitas dalam statistik parametris memberikan syarat bahwa setiap variabel yang akan dianalisis harus berdistribusi norma,Uji korelasi yang bertujuan untuk mengetahui ada atau tidaknya pengaruh pada kedua variabel dan uji hipotesis Pada penelitian ini, uji t digunakan untuk mengetahui sejauh mana variabel kompetensi guru mampu menjelaskan pengaruh terhadap variabel hasil belajar.

Penelitian ini menggunakan metode eksperimen dan untuk memperoleh data-data yang dibutuhkan untuk mengetahui motivasi belajar siswa, dan hasil belajar siswa menggunakan model Cooperative Tipe Jigsaw disekolah.. Sebagai populasi dan sampel dalam penelitian ini 35 siswa di kelas V. Berdasarkan teknik sampel jenuh. Instrument yang dihunakan dalam penelitian ini adalah angket motivasi belajar sebanyak 25 pernyataan dan soal pre-test dan post test 33 butir soal yang akan diberikan kepada siswa kelas V SD RK Budi Luhur Medan Denai Tahun Pembelajaran 2020/2021.

\section{HASIL DAN PEMBAHASAN}

Pada bagian ini akan di deskripsikan gambaran mengenai pengaruh motivasi belajar terhadap hasil belajar tema 8 melalui model Cooperative Tipe Jigsawkelas V SD RK Budi Luhur Medan Tahun Pembelajaran 2020/2021. Data pada variabel motivasi belajar siswa dengan menggunakan instrument angket dengan 25 pernyataan dengan 35 responden, setiap butir pernyataan memiliki lima alternative jawaban. Berdasarkan perhitungan statistik dasar diperoleh rata-rata (mean) 80,45. Data yang diperoleh selanjutnya dibuat tabel frekuensi model pembelajaran yang cara singkat dapat dilihat pada tabel 1 .

Tabel 1. Frekuensi Motivasi Belajar

\begin{tabular}{crccl}
\hline No & Skor & Frekuensi & Persentase & \multicolumn{1}{c}{ Kategori } \\
\hline 1 & $85.7-95.9$ & 17 & $48 \%$ & Sangat Tinggi \\
2 & $78.9-85.7$ & 8 & $22 \%$ & Tinggi \\
3 & $72.1-78.9$ & 2 & $5 \%$ & Cukup \\
4 & $65.3-72.1$ & 1 & $2 \%$ & Kurang \\
5 & $55.1-65.3$ & 7 & $20 \%$ & Rendah \\
\hline
\end{tabular}


Berdasrkan tabel 1 frekuensi motivasi belajar pada kategori sangat tinggi sebesar $48 \%$, pada kategori tinggi sebesar $22 \%$, pada kategori cukup 5\%, pada kategori kurang $2 \%$ dan pada kategori rendah sebesar $20 \%$. Untuk lebih jelasnya dapat dilihat dari diagram berikut:

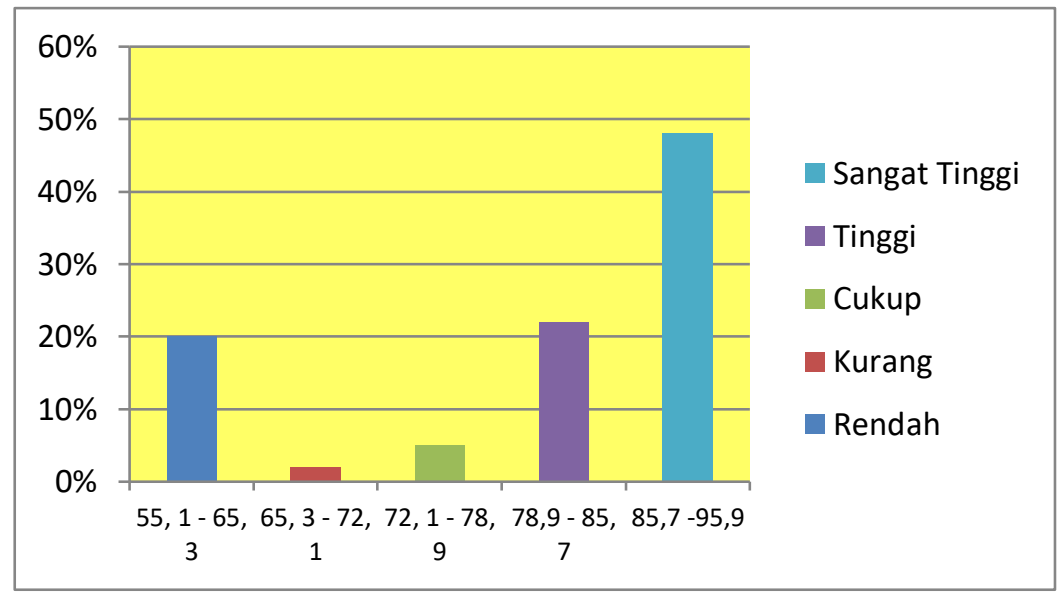

Gambar 1. Diagram Motivasi Belajar

Berdasarkan diagram di atas dapat disimpulkan bahwa motivasi belajar di SD RK Budi Luhur Medan Denai dalam kategori yaitu sangat tinggidengan jumlah 17 responden, selain itu paling rendah adalah skor 65.3-72.1 dengan jawaban 2\% dengan kategori kurang jumlah 1 responden.

Data pada nilai pre-test dengan tidak diberikan perlakuan dan post test yang sesudah diberikan perlakuaan Hal ini dilakukan untuk mengetahui rata-rata (mean), standar deviasi (SD) dan standar error (SE) dari data hasil post test yang diberikan kepada siswa melalui perhitungan dibawah ini. Standar deviasi adalah suatu mengambarkan seberapa besar perbedaan nilai sampel terhadap rata-ratanya, dan standar error adalah sebagai standar deviasi dari rata-rata sampel.

Maka dapat dilihat nilai post test lebih tinggi dibandingkan nilai pre-test di kelas V SD RK Budi Luhur Medan Tahun Pembelajaran 2020/2021. Dan dapat dilihat dari gambar dibawah ini.

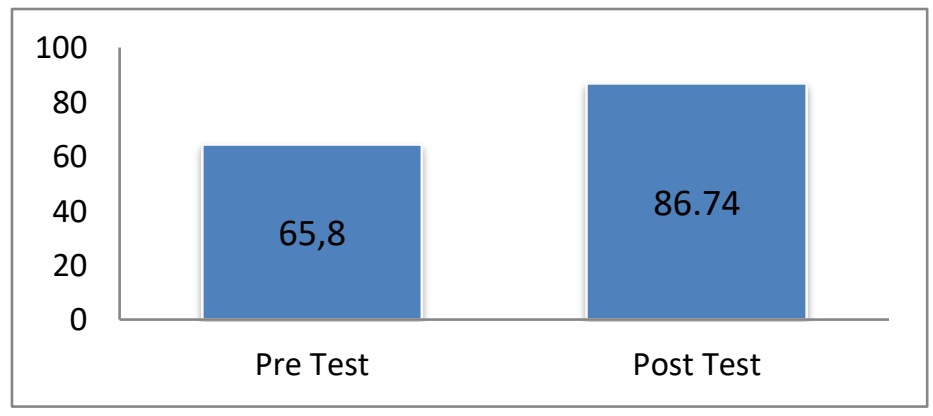

Gambar 2. Diagram Soal Pre-test dan Post Test 
Berdasarkan diagram tabel tersebut dapat disimpulkan bahwa nilai eksperimen sebelum diberikan perlakuaan model pembelajaran Cooperative Tipe Jigsaw dengan rata-rata siswa 65.8 kategori cukup.Setelah diberikan perlakuaan model pembelajaran Cooperative Tipe Jigsaw ratarata siswa 86.74 kategori baik sekali dapat disimpulkan bahwa nilai post teks sudah mencapai KKM yaitu 70 .

Tabel 2. Kriteria Penelitian Pada Pre-test dan Post Test

\begin{tabular}{cc}
\hline Kriteria Penelitian & Keterangan \\
\hline $80-100$ & Baik sekali \\
$70-79$ & Baik \\
$60-69$ & Cukup \\
$50-59$ & Kurang \\
$0-49$ & Gagal
\end{tabular}

Dapat dilihat nilai post test lebih tinggi dibandingkan nilai pre-test.Setelah dilakukan perhitungan dengan menggunakan SPSS Versi 22.0 pengujian normalitas yaitu dengan menggunakan uji Kolmogorov-Smirnov, diketahui nilai signifikansi $0.05 \%$.

Tabel 3 Uji Normalitas

\begin{tabular}{llr}
\hline & & $\begin{array}{c}\text { Unstandardized } \\
\text { Residual }\end{array}$ \\
\hline $\mathrm{N}$ & & 35 \\
Normal Parameters & Mean & .0000000 \\
& Std. & 4.16127706 \\
& Deviation & .167 \\
Most Extreme Differences & Absolute & .133 \\
& Positive & -.167 \\
Test Statistic & Negative & .167 \\
Asymp. Sig. (2-tailed) & & $.200^{\mathrm{c}}$ \\
\hline
\end{tabular}

Berdasarkan uji normalitas diketahui bahwa nilai signifikan Asiymp, signifikan (2tailed) sebesar 0.200 lebih besar dari 0.05. Maka sesuai dengan dasar pengambilan keputusan dalam uji normalitas Kolmogorov-Smirnov jika > 0.05 maka $\mathrm{H}_{\mathrm{a}}$ diterima (berdistribusi normal) dan jika taraf signifikan yang diperoleh $<0.05$ maka $\mathrm{H}_{\mathrm{o}}$ ditolak (tidak berdistribusi normal)dapat disimpulkan bahwa data berdistribusi normal.
Analisis korelasi dengan menggunakan rumus $\mathrm{r}_{\mathrm{xy}}$ bertujuan untuk membuktikan adanya pengaruh yang signifikan antara variabel $\mathrm{x}$ dengan variabel y. Uji normalitas bertujuan untuk mengetahui apakah dalam penelitian tersebut berdistribusi normal atau tidak.Dapat dilihat dari tabel dibawah ini. 
Tabel 4. Uji Korelasi

\begin{tabular}{|c|c|c|c|}
\hline & & Motivasi & Hasil \\
\hline \multirow[t]{3}{*}{ Motivasi } & $\begin{array}{l}\text { Pearson } \\
\text { Correlation }\end{array}$ & 1 & $.880^{* *}$ \\
\hline & Sig. (2-tailed) & & .000 \\
\hline & $\mathrm{N}$ & 35 & 35 \\
\hline \multirow[t]{3}{*}{ Hasil } & $\begin{array}{l}\text { Pearson } \\
\text { Correlation }\end{array}$ & $.880^{* *}$ & \\
\hline & Sig. (2-tailed) & .000 & \\
\hline & $\mathrm{N}$ & 35 & 35 \\
\hline
\end{tabular}

Berdasarkan hasil perhitungan yang dilakukan diperoleh hasil koefisien korelasi $\left(\mathrm{r}_{\mathrm{xy}}\right)$ yaitu $\mathrm{r}_{\text {hitung }}=0.880 \geq \mathrm{r}_{\text {tabel }}=0.334$. Maka dapat disimpulkan hipotesis alternatif $\left(\mathrm{H}_{\mathrm{a}}\right)$ diterima yaitu terdapat hubungan positif yang signifikan antara motivasi dan model Cooperative Tipe Jigsaw dengan hasil belajar siswa SD RK Budi Luhur Medan.

Pengujian hipotesis pada penelitian ini dilakukan dengan menggunakan uji $\mathrm{t}$ dengan berbantuan program SPSS Versi 22.0. Uji t digunakan untuk mengetahui ada tidaknya pengaruh variabel bebas terhadap variabel terikat yaitu motivasi belajar terhadap hasil belajar siswa menggunakan model Cooperetive Tipe Jigsaw. Pengujian hipotesis dengan menggunakan uji $t$ dilakukan dengan cara membandingkan $t_{\text {hitung }}$ dengan $t_{\text {tabel.. }}$ Kriteria pengujian dengan menggunakan uji $t$ adalah jika $t_{\text {hitung }} \geq t_{\text {tabel }}$ hipotesis alternatif diterima dan jika $t_{\text {hitung }} \leq t_{\text {tabel }}$ hipotesis alternatif ditolak. Berdasarkan hasil perhitungan yang dilakukan dengan bantuanprogram SPSS Versi 22.0, maka diperoleh hasil uji-tsebesar 10.618 dan $t_{\text {tabel }}$ 1.697. Maka Ha diterima yaitu terdapat pengaruh motivasi dan model Cooperative Tipe Jigsaw terhadap hasil belajar siswa di SD RK Budi Luhur Medan Denai.

\section{SIMPULAN DAN REKOMENDASI}

Berdasarkan hasil penelitian dengan menerapakan motivasi belajar dan menggunakan model Cooperative Tipe Jigsaw diperoleh kesimpulan yaitu dengan memberikan semangat, dukungan, dorongan dan mungganakan model pembelajaran saat proses pembelajaran pada tema lingkungan sahabat kita sub tema 1 manusia dan lingkungan pembelajaran 1 dapat meningkatkan hasil belajar siswa. Dan dengan memeberikan motivasi belajar dan menggunakan model pembelajaran juga mengalamai peningkatan yang tidak membuat siswa merasa bosan, jenuh dan mengantuk di dalam kelas siswa kelas V di SD RK Budi Luhur Medan Denai Tahun Pembelajaran 2020/2021. Berdasarkan hasil penelitian dan kesimpulan yang telah dipaparkan, maka saran yang dapat disampaikan oleh peneliti untuk Sekolah yaitu perlunya memberikan motivasi belajar dan melakukan model pembelajaran didalam kelas karena hal itu dapat membantu pihak sekolah untuk mengetahui perkembangan hasil belajar siswa, bagi guru hendaknya menggunakan sumber-sumber belajar yang bervariasi dan menarik perhatian siswa untuk siswa dengan mengetahui adanya pengaruh motivasi belajar dan model Cooperative Tipe Jigsaw terhadap hasil belajar siswa, diharapkan siswa dapat meningkatkan hasil belajar dengan motivasi dan model pembelajaran yang akan digunakan oleh guru.

\section{DAFTAR PUSTAKA}

Anurahman. (2014). Belajar dan Pembelajaran (9th ed.). Alfabeta.

Arikunto. (2018). Prosedur Penelitian (14th ed.). PT Rineka Cipta.

Dalyono. (2012). Psikologi Pendidikan (7th ed.). Jakarta: PT Rineka Cipta.

Dimyanti, \& Mudjiono. (2015). Pelajaran dan Pembelajaran (5th ed.). jakarta: PT Rineka Cipta.

Djaali. (2014). Psikologi Pendidikan (8th ed.). Jakarta: PT bumi aksara.

Djamarah. (2019). Psikologi Belajar (3rd ed.). Jakarta: PT Rineka Cipta. 
Hamalik. (2013). Kurikulum dan Pembelajaran (12th ed.). Jakarta: PT bumi Aksaea.

Hamzah. (2014). Teori Motivasi \& Pengukurannya (14th ed.). Jakarta: PT bumi aksara.

Hariadi, S., Haris, M., \& Junaidi, E. (2019). Pengaruh Model Pembelajaran Kooperatif Tipe Jigsaw Terhadap Hasil Belajar Kimia. In Chemistry Education Practice (Vol. https://doi.org/10.29303/cep.v2i2.1288

Istirani, \& Pulungan. (2018). Ensiklopedia Pendidikan (2nd ed.; Anwar sembiring, ed.). Medan.

Khairani. (2018). Psikologi Belajar (13, ed.). Yogyakarta: Aswaja pressindo.

Kompri. (2018). Motivasi Pembelajaran Perseptif Guru dan Siswa (A. Kamsyach (ed.); 2nd ed.). PR remaja rosdakarya.

Muliawan. (2016). 45 Model Pembelajaran Spektakuler (Nurhid (ed.); 1st ed.). ARruzz media.

Ngalimun. (2017). Strategi dan Model Pembelajaran (1st ed.). Yogyakarta: Aswaja pressindo.

Nurkhayati. (2017). Pengaruh Model Pembelajaran Kooperatif Tipe Jigsaw Dengan Media Gambar Program Studi Pendidikan Guru Sekolah Dasar.

Pasaribu, M. F., Tanjung, D. S., \& Azelina, D. (2020). Pengaruh Keterampilan Mengajar Guru terhadap Motivasi Belajar Siswa di Kelas V SDN 04 Pangkatan. Jurnal Educatio FKIP UNMA, 6(2), 269. https://doi.org/10.31571/sosial.v6i2.1294

Prestowo. (2014). Bahan Ajar Tematik (1st ed.). Jakarta: 2014.

Priansa. (2015). Manajemen peserta Didik dan Model Pembelajaran (1st ed.; A. Kasmanah, ed.). Bansung: Alfabeta.

Purba, J. M., Sinaga, R., \& Tanjung, D. S. (2020). Pengaruh Model Pembelajaran Tipe Kooperatif Tipe Scramble terhadap Hasil Belajar Siswa pada Tema Daerah Tempat Tinggalku Kelas IV. ESJ (Elementary School Journal), 10(4), 216-224.
Purwanto. (2011). Evaluasi hasil belajar (3rd ed.; B. Santoso, ed.). Yogyakarta: Pustaka Pelajar.

Ramadhani, A. (2019). Pengaruh Motivasi Dan Disiplin Belajar Terhadap Hasil Belajar Ipa Siswa Kelas V Sd Negeri Gugus Ki Hajar Dewantara Kecamatan .... Retrieved from http://lib.unnes.ac.id/34786/

Rosyid, \& Abdulah. (2018). Reward \& Punishment dalam Pendidikan (1st ed.). Malang: Literasi nusantara.

Satria, M., Masyhud, S., \& Yuliati, N. (2014). Terhadap Hasil Belajar Mata Pelajaran IPA. 1-4.

Simarmata, E. J., Rajagukguk, N., \& Anzelina, D. (2020). Upaya Peningkatan Hasil Belajar Siswa dengan Menggunakan Model Pembelajaran Talking Stick pada Tema Indahnya Kebersamaan di Kelas IV SD Negeri 097375 Tiga Raja. Guru Kita, 4(4), $1-11$.

Simorangkir, F. M. A., \& Tanjung, D. S. (2019a). Analisis Pelaksanaan Pembelajaran Tematik Dengan Pendekatan Multiple Intelligencesberbasis Budaya Batak Angkola Untuk Siswa Kelas Iv Sekolah Dasar. Jurnal Education and Development, 7(4), 302-304.

Simorangkir, F. M. A., \& Tanjung, D. S. (2019b). Implementation of Multiple Intelligences Approach Based On Batak Angkola Culture in Learning Thematic For Class IV SD Negeri 100620 Pargarutan Julu South Tapanuli District. Budapest International Research and Critics in Linguistics and Education (BirLE) Journal, 2(4), 547551.

https://doi.org/10.33258/birle.v2i4.538

Sugiyono. (2017). Metode Penelitian Kuantitatif, Kualitataif dan $R \& D$ (25th ed.). Alfabeta.

Tanjung, D. (2016). meningkatkan hasil belajar IPS siswa dengan menerapkan model pembelajaran kooperatif tipe time gemes tournament (TGT) di kelas V SDN 200111 Padang sidempuan. IV. 
Jurnal PAJAR (Pendidikan dan Pengajaran)

Volume 5 Nomor 5 September 2021 | ISSN Cetak : 2580 - 8435 | ISSN Online : 2614 - 1337

DOI : http://dx.doi.org/10.33578/pjr.v5i5.8454

Yusuf, \& Sugandhi. (2013). Perkembangan

Peserta Didik (4th ed.). Jakarta: PT

rajagrafindo persada. 